\title{
Gender differences of polymorphisms in the TF and TFPI genes, as related to phenotypes in patients with coronary heart disease and type-2 diabetes
}

\author{
Trine B Opstad*1, Alf Åge Pettersen1', Thomas Weiss ${ }^{1}$, Harald Arnesen 1,3 and Ingebjørg Seljeflot 1,2,3
}

\begin{abstract}
Background: Tissue factor (TF) and its inhibitor tissue factor pathway inhibitor (TFPI) are the main regulators of the initiation of the coagulation process, important in atherothrombosis. In this study we have investigated the frequency of six known TF and TFPI single nucleotide polymorphisms (SNPs) in CHD patients as compared to healthy individuals. These genotypes and the phenotypes (TF, TFPI free and total antigen) were evaluated with special reference to gender and diabetes in the CHD population.

Methods: Patients with angiographically verified CHD ( $n=1001 ; 22 \%$ women, $20 \%$ diabetics), and 204 healthy controls (28\% women), were included. The investigated SNPs were: TF -1812C/T and TF -603A/G in the 5'upstream region, TF 5466A/G in intron 2, TFPI -399C/T and TFPI -287T/C in the 5'upstream region and the TFPI -33T/C in intron 7.

Results: No significant differences in frequencies between the CHD population and the controls of any polymorphisms were observed. In the CHD population, the TF 5466 A/G SNP were significantly more frequent in women as compared to men $(p<0.001)$. The TF-1812C/T and the TF-603A/G SNPs were significantly more frequent in women without type2 diabetes compared to those with diabetes ( $p<0.018$, both), and the heterozygous genotypes were associated with significantly lower TF plasma levels compared to the homozygous genotypes ( $p<0.02$, both).

The TFPI-399C/T and the TFPI-33T/C SNPs were associated with lower and higher TFPI total antigen levels, respectively ( $p<0.001$, both).

Conclusion: Genetic variations in the TF and TFPI genes seem to be associated with gender and type-2 diabetes, partly affecting their respective phenotypes.
\end{abstract}

\section{Background}

Tissue factor (TF) and its endogenous inhibitor, tissue factor pathway inhibitor (TFPI) are the main regulators of the initiation of the coagulation process, important in atherothrombosis. Injury of the vessel wall and rupture of an atherosclerotic plaque lead to exposure of TF to circulating blood, followed by an activation of the haemostatic system. In addition, blood-borne, or soluble TF (TF) from micro particles and monocytes may represent thrombogenic potential [1]. TFPI is the main regulator in the initial step of the coagulation cascade mediated by TF, by

\footnotetext{
* Correspondence: trineoa@medisin.uio.no

${ }^{1}$ Center for Clinical Heart Research, Department of Cardiology, Oslo University Hospital Ulleval, Oslo, Norway

Full list of author information is available at the end of the article
}

binding to coagulation factors Xa, VIIa and TF forming an inactive complex $[2,3]$. TFPI, mainly produced by the endothelium [4], is predominantly associated with lipoproteins in the blood [2,5] or is endothelial-bound [6], whereas a small portion circulates as free molecules. Enhanced TF expression has been found in atherosclerotic plaques [7], in which TFPI has been found to colocalize [8].

Elevated levels of TF has been associated to cardiovascular disease (CVD) [9-11] and also shown to be predictive for future events in some studies [12,13], whereas the role of TFPI in atherothrombosis remains unclear. However, a positive correlation between plasma levels of TF and TFPI in ischemic heart disease has been demonstrated [9]. 
The association between CVD and type- 2 diabetes mellitus (T2DM) is well established. It has also been shown, that women with coronary heart disease (CHD) more often present T2DM than men [14,15], however, the cause and molecular mechanism underlying this relationship is not fully explored. The atherosclerotic process includes both environmental and multiple genetic factors, leading to the unfavorable state in the cardiovascular system. The accelerated atherosclerosis seen in diabetic patients might be a consequence of chronic hyperglycemia [16]. Permanent hyperglycemia may lead to glycosylation of proteins, including albumin, and the latter has been shown to increase the expression of TF in monocytes [17]. Further, elevated levels of circulating TF-procoagulant activity have been demonstrated in patients with T2DM [18]. Hyperglycemia may also lead to dysfunctional endothelium in which TFPI, suggested to be a marker of endothelial dysfunction, may be affected [19]. Both genetic and environmental risk factors are able to modify the expression of proteins, and several genetic variants in the TF and TFPI gene have been investigated in relation to CHD [20-26]. Single nucleotide polymorphisms (SNPs) may affect the levels of their gene encoding products, leading to a modified susceptibility to CHD.

In the present study we aimed to investigate the frequency of six known SNPs in the genes coding for TF and TFPI in patients with CHD, as compared to healthy individuals, and furthermore to explore the influence of these SNPs on plasma levels of the proteins, with special emphasis on diabetes and gender differences in a CHD population. The choice of the investigated polymorphisms is based on previous research in the field.

The results of the present study indicate differences in frequencies of the TF polymorphisms as related to diabetes and gender, and additionally changes in plasma levels according to the different TF and TFPI SNPs.

\section{Methods \\ Study population}

We studied 1001 patients enrolled in the Aspirin nonresponsiveness and clopidogrel clinical endpoint trial (ASCET) [27]. All patients had angiographically verified stable CHD and $97 \%$ were Caucasians. The mean age was 62 years and $22 \%$ were women. Twenty percent had T2DM, defined as known T2DM or fasting glucose $>7$ $\mathrm{mmol} / \mathrm{l}, 44 \%$ had experienced an acute myocardial infarction (MI). The control group consisted of 204 apparently healthy controls, mean age 55 years, $28 \%$ being women, all Caucasians. They were included after clinical examination and an ECG-test, to rule out any clinical evidence for atherosclerotic disease. The study was approved by the Regional Ethics Committee and all patients gave their written informed consent to participate. The ASCET study is registered at the website; clinicaltrials.gov, with the identification number: NCT00222261

\section{Blood sampling}

Venous blood was collected by standard venipuncture between 8 and 10 a.m. in fasting condition and without intake of any medication. Citrated plasma $(0.129 \mathrm{M}$ in dilution 1:10), stored on ice, was separated within 30 minutes by centrifugation at $4^{\circ} \mathrm{C}$ and $3.000 \times$ g for 20 minutes. For genotype determination, also performed in the healthy controls, whole blood collected in EDTA tubes was used. All samples were stored at $-80^{\circ} \mathrm{C}$ until analyzed. Serum lipids, glucose and $\mathrm{HbA1c}$, were determined by conventional routine methods.

\section{DNA isolation}

DNA was purified from whole blood (EDTA) on the Magna Pure LC Instrument (Roche Diagnostics GmbH, Mannheim, Germany), using MagNA Pure DNA LC isolation kit, Large Volume (Roche Diagnostics $\mathrm{GmbH}$ ). The DNA Large Volume Blood Protocol of the MagNA Pure software program, version 3.0, was used for extraction with settings for an initial sample volume of $500 \mu \mathrm{l}$ and an elution volume of $100 \mu \mathrm{l}$. DNA purity and quantity were tested on the NanoDrop, ND-1000 (Saveen Werner, Sweden) and DNA was kept at $-80^{\circ} \mathrm{C}$ until analyzed.

\section{Genotype analysis}

The TF $-1812 \mathrm{C} / \mathrm{T}$ (rs 958587) and TF -603A/G (rs 1361600) in the 5'upstream region, TF $5466 \mathrm{~A} / \mathrm{G}$ (rs3917643) in intron 2, the TFPI -399C/T (rs 10153820) and TFPI $-287 \mathrm{~T} / \mathrm{C}$ (rs 10931292) in the 5'upstream region, and the TFPI -33T/C (rs 8176592) in intron 7 polymorphisms were investigated. Further, the haplotype TF I (TF -1812CC combined with TF 5466 AA/AG) was investigated. Allelic discrimination was performed by the Applied Biosystems 7900HT Fast Real-Time PCR system, using allele specific primers and probes included in the Taqman SNP Genotyping assay (TaqMan MGB probes; FAM and VIC dye-labeled) and the TaqMan Genotyping Master Mix, (Applied Biosystems, Foster City, CA, USA). A final reaction volume of $25 \mu \mathrm{l}$ was used and 1-20 ng of genomic DNA was added. The Thermal Cycler Conditions were the same for all polymorphisms with an initial step of $10 \mathrm{~min}$ at $95^{\circ} \mathrm{C}$ followed by 47 cycles of $15 \mathrm{sec}$ at $92^{\circ} \mathrm{C}$ and $1 \mathrm{~min}$ at $60^{\circ} \mathrm{C}$ each.

\section{Plasma TF and TFPI analyses}

Levels of TF and TFPI were measured using commercial ELISA kits; the Imubind TF kit, recognising TF-apo, TF and TF-VII complexes (American Diagnostic Inc., Greenwich, CT, USA), and the Asserachrom TFPI free antigen and Asserachrom TFPI total antigen kits, recognising the full-length TFPI molecules, and the full-length and trun- 
cated TFPI molecules including TFPI bound to lipoproteins, respectively (Stago Diagnostica, Asnière, France). The inter-assay coefficients of variation in our laboratory were $7.9 \%, 5.6 \%$ and $3.8 \%$, respectively.

\section{Statistical analysis}

The $x^{2}$ test was used to test for deviation of the genotype distribution from Hardy-Weinberg equilibrium. Allele frequencies were evaluated by gene counting and group differences for each polymorphism were examined by chi $x^{2}$ test. Student $t$-test or Mann-Whitney test and Kruskall-Wallis test, when appropriate, were used for comparing TF and TFPI levels between two or more groups. Two-tailed probability values of 0.05 or less were considered statistically significant. Exact p-values are given, except when $p<0.001$ or $p>0.2$. All statistical analyses were performed in SPSS 16.0 (SPSS Inc., Chicago, IL, USA).

\section{Results}

\section{Clinical characteristics}

Baseline characteristics of the included CHD patients are shown in Table 1. All patients were optimally treated,

Table 1: Characteristics of the CHD population $(n=1001)$.

\begin{tabular}{ll}
\hline Age (years, mean (range)) & $62(36-81)$ \\
Men/Women (\%) & $783 / 218(78 / 22)$ \\
Diabetes Mellitus n (\%) & $200(20)$ \\
Myocardial infarction n (\%) & $436(44)$ \\
Hypertension n (\%) & $553(56)$ \\
SBP (mmHg) & $139.4(19.3)$ \\
DBP (mmHg) & $82.1(9.7)$ \\
Current smokers $\mathrm{n}(\%)$ & $204(20.4)$ \\
BMI (kg/m²) & $27.9(11.5)$ \\
Total cholesterol (mmol/l) & $4.6(1.0)$ \\
HDL cholesterol (mmol/l) & $1.3(0.4)$ \\
LDL cholesterol (mmol/l) & $2.5(0.8)$ \\
Triglycerides (mmol/l) & $1.6(1.1)$ \\
Fasting glucose (mmol/l) & $6.0(1.9)$ \\
HbA1c (\%) & $6.0(0.9)$ \\
Medication \% & \\
$\quad$ Statins & 98 \\
Aspirin & 100 \\
$\beta$-Blockers & 76 \\
Nitrates & 22 \\
ACE inhibitors & 26 \\
\hline Values are mean (SD) or number (propotions)
\end{tabular}

Values are mean (SD) or number (proportions) if not otherwise stated.

SBP: systolic blood pressure; DBP: diastolic blood pressure; BMI: body mass index; ACE:

angiotensin converting enzyme. thus, $100 \%$ were on aspirin and $98 \%$ on statin treatment. Blood samples for genotyping in the CHD group was detectable in 996 samples. For phenotype analysis, only performed in the CHD population, measurements of TF were complete in 983 individuals and of TFPI in 1000.

\section{Genotype distribution and allelic frequencies}

The distribution of the TF and TFPI SNPs in CHD patients and healthy controls is shown in Table 2. All SNPs conformed to the Hardy-Weinberg equilibrium. The two TF polymorphisms at positions -1812 and -603 were found to be completely concordant in 1199 of the total of 1200 individuals. No significant case-control differences in frequencies of any TF polymorphisms were observed, also not when analyzing for the TF I haplotype. When analyzing the three variants of the TF -1812 and the TF -603 SNP's separately, the results were similar. Also for the TFPI SNPs no differences in frequencies between CHD and healthy controls were found.

In the CHD population, the differences in genotype distribution between gender and in patients with T2DM or not, are shown in Table 3. The TF 5466 polymorphism was significantly more frequent in women, as compared to men (OR 2.23, 95\% CI 1.48-3.37, $\mathrm{p}<0.001$ ), and this was also true when analyzing for the TF I haplotype (OR 2.56 95\% CI 1.52-4.31, $\mathrm{p}<0.001$ ). The TF -1812 and the TF -603 polymorphisms were less, but not significantly, abundant in women $(\mathrm{p}=0.124$ and 0.115 , respectively). The TFPI -399 polymorphism was more common in women $(p=0.075)$. No difference in frequencies was seen for any genotype between patients presenting with T2DM or not, or between patients who had previously experienced MI or not (data not shown).

Due to gender differences, we evaluated the T2DM genotype distribution in the subgroup of women $(\mathrm{n}=$ 218) (Table 4). The TF - 1812 and the TF - 603 polymorphisms were significantly less frequent in CHD women with T2DM as compared to women without (OR 0.45, $95 \%$ CI 0.14-0.88, $\mathrm{p}=0.018$ for both). These associations were not observed in men (data not shown).

\section{Plasma levels of TF and TFPI according to genotypes and disease state and gender}

To evaluate the influence of the investigated SNPs on the $\mathrm{TF}$ and TFPI plasma levels, the biomarkers were measured in the total CHD population (Table 5). Patients presenting with the TF -1812 and TF -603 polymorphisms showed significant differences in the TF levels, with the heterozygous $(\mathrm{n}=466)$ having the lowest levels $(\mathrm{p}=0.013$ and 0.019 , respectively). The TFPI -399 and the TFPI -33 polymorphisms were associated with significantly lower and higher TFPI total antigen levels, respectively $(\mathrm{p}<$ 0.001 for both). 
Table 2: Frequency of the TF and TFPI polymorphisms in CHD patients and healthy controls

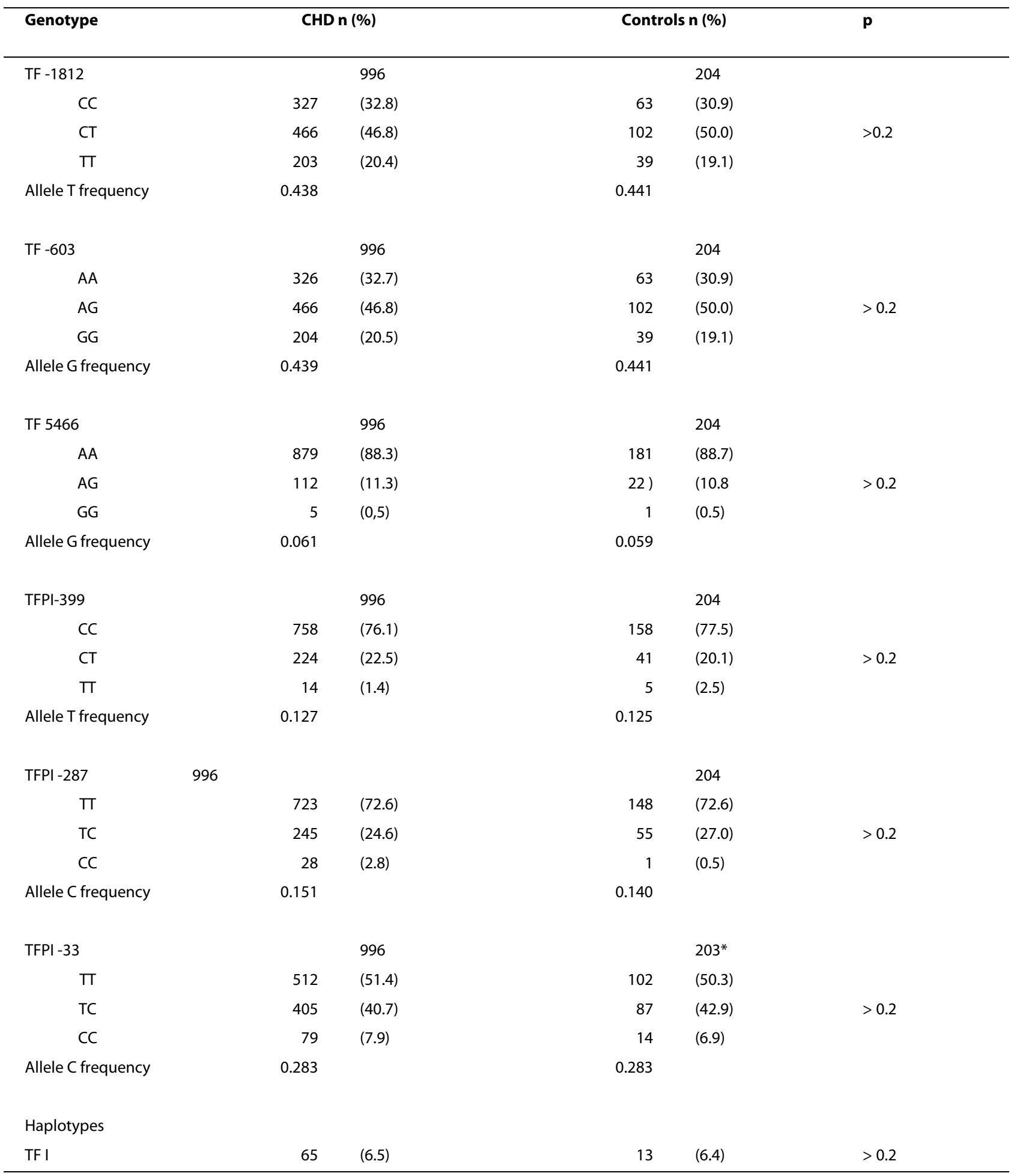

Calculations are performed with comparison of the heterozygous and homozygous pooled, versus the wild type.

Haplotypes: TFI is the combination of TF -1812 CC and TF 5466 AG/GG

$\mathrm{p}$-values refer to differences between $\mathrm{CHD}$ patients and controls.

*The TFPI -33 polymorphism was detectable in 203 out of 204 controls. 
Table 3: Association between TF and TFPI polymorphisms in subgroups of the CHD population

\begin{tabular}{|c|c|c|c|c|c|c|}
\hline Genotype & $\begin{array}{l}\text { No with } \\
\text { T2DM+/- }\end{array}$ & \% with T2DM & p-value & $\begin{array}{l}\text { No of Male/ } \\
\text { Female }\end{array}$ & $\%$ Female & p-value \\
\hline \multicolumn{7}{|l|}{ TF -1812} \\
\hline $\mathrm{CC}$ & $71 / 256$ & 22 & & $246 / 81$ & 25 & \\
\hline $\mathrm{CT}$ & $93 / 373$ & 20 & $>0.2$ & $366 / 100$ & 21 & 0.124 \\
\hline$\pi$ & $35 / 168$ & 17 & & $166 / 37$ & 18 & \\
\hline \multicolumn{7}{|l|}{ TF -603} \\
\hline AA & $71 / 255$ & 22 & & $245 / 81$ & 25 & \\
\hline$A G$ & $93 / 373$ & 20 & $>0.2$ & $366 / 100$ & 21 & 0.115 \\
\hline GG & $35 / 169$ & 17 & & $167 / 37$ & 18 & \\
\hline \multicolumn{7}{|l|}{ TF 5466} \\
\hline $\mathrm{AA}$ & 179/700 & 20 & & $703 / 176$ & 20 & \\
\hline AG & $19 / 93$ & 17 & $>0.2$ & $72 / 40$ & 36 & $<0.001$ \\
\hline GG & $1 / 4$ & 20 & & $3 / 2$ & 40 & \\
\hline \multicolumn{7}{|l|}{ TFPI -399 } \\
\hline $\mathrm{CC}$ & $151 / 607$ & 20 & & $602 / 156$ & 21 & \\
\hline $\mathrm{CT}$ & $45 / 179$ & 20 & $>0.2$ & $166 / 58$ & 26 & 0.075 \\
\hline$\pi$ & $3 / 11$ & 21 & & $10 / 4$ & 29 & \\
\hline \multicolumn{7}{|l|}{ TFPI -287 } \\
\hline$\pi$ & $145 / 578$ & 20 & & $564 / 159$ & 22 & \\
\hline $\mathrm{TC}$ & $49 / 196$ & 20 & $>0.2$ & $194 / 51$ & 21 & $>0.2$ \\
\hline $\mathrm{CC}$ & $5 / 23$ & 18 & & $20 / 8$ & 29 & \\
\hline \multicolumn{7}{|l|}{ TFPI -33} \\
\hline$\pi$ & $97 / 415$ & 19 & & $399 / 113$ & 22 & \\
\hline $\mathrm{TC}$ & $87 / 318$ & 22 & $>0.2$ & $315 / 90$ & 22 & $>0.2$ \\
\hline $\mathrm{CC}$ & $15 / 64$ & 19 & & $64 / 15$ & 19 & \\
\hline \multicolumn{7}{|l|}{ Haplotypes } \\
\hline TFI & $13 / 35$ & 20 & $>0.2$ & $39 / 26$ & 40 & $<0.001$ \\
\hline
\end{tabular}

Calculations are performed with comparison of the heterozygous and homozygous pooled, versus the wild type. Haplotypes: TFI is the combination of TF -1812 CC and TF 5466 AG/GG

$\mathrm{p}$-values refer to differences between disease states and gender, as related to genotype.

No differences according to the presence of T2DM or gender were observed (Additional file 1). The patients who had previously experienced MI $(n=436)$ had significantly higher TFPI total antigen levels as compared to the subjects without MI $(\mathrm{p}=0.008)$.

Based on the gender differences in genotypes, we further analyzed for phenotype in women alone according to disease state (Additional file 2). TFPI total antigen levels were lower in females with T2DM $(\mathrm{n}=46)$ as compared to those without $(\mathrm{p}=0.093)$. When analyzing specifically for the different genotypes, the TFPI levels in T2DM women bearing the major allele of TFPI -399 and TFPI 287 were significantly lower compared to women without T2DM ( $<0.05$ for both) (Figure 1). TFPI free antigen levels were significantly higher in females previously suf- fering MI $(\mathrm{n}=71)$ as compared to non-MI women $(\mathrm{p}=$ 0.013) (Additional file 2), mainly observed in those bearing the minor allele of the TFPI -399 and the TFPI -33 polymorphisms, and in subjects homozygous for the major TFPI -287 allele (Figure 1). In men, the TFPI total antigen was significantly higher in MI patients, irrespective of genotype $(\mathrm{p}=0.025)$ (data not shown).

\section{Discussion}

In this study we could show that the investigated genetic variants of the TF and the TFPI genes were not differently distributed between CHD patients and healthy controls. It seems therefore that these polymorphisms alone not necessarily dispose for the disease. They might, nevertheless, contribute to an increased susceptibility. As CHD 
Table 4: Frequencies of TF and TFPI polymorphisms in women with CHD according to T2DM or not

\begin{tabular}{|c|c|c|c|}
\hline Genotype & T2DM+ (46) n(\%) & T2DM- (172) n(\%) & $\mathbf{p}$ \\
\hline \multicolumn{4}{|l|}{ TF -1812} \\
\hline $\mathrm{CC}$ & $24(52.2)$ & $57(33.1)$ & 0.018 \\
\hline $\mathrm{CT}$ & $17(37.0)$ & $83(48.3)$ & \\
\hline$\pi$ & $5(10.9)$ & $32(18.6)$ & \\
\hline Allele T frequency & 0.294 & 0.428 & \\
\hline \multicolumn{4}{|l|}{ TF -603} \\
\hline $\mathrm{AA}$ & $24(52.2)$ & $57(33.1)$ & 0.018 \\
\hline AG & $17(37.0)$ & $83(48.3)$ & \\
\hline GG & $5(10.9)$ & $32(18.6)$ & \\
\hline Allele G frequency & 0.294 & 0.428 & \\
\hline \multicolumn{4}{|l|}{ TF 5466} \\
\hline $\mathrm{AA}$ & $36(78.3)$ & $140(81.4)$ & $>0.2$ \\
\hline AG & $9(19.6)$ & $31(18.0)$ & \\
\hline GG & $1(2.2)$ & $1(0.6)$ & \\
\hline Allele $G$ frequency & 0.120 & 0.096 & \\
\hline \multicolumn{4}{|l|}{ TFPI -399} \\
\hline $\mathrm{CC}$ & $37(80.4)$ & $119(69.2)$ & 0.133 \\
\hline $\mathrm{CT}$ & 9 (19.6) & $49(28.5)$ & \\
\hline$\pi$ & 0 & $4(2.3)$ & \\
\hline Allele T frequency & 0.098 & 0.166 & \\
\hline \multicolumn{4}{|l|}{ TFPI -287} \\
\hline$\pi$ & 34 (73.9) & $125(72.7)$ & $>0.2$ \\
\hline $\mathrm{TC}$ & $9(19.6)$ & $42(24.4)$ & \\
\hline $\mathrm{CC}$ & $3(6.5)$ & $5(2.9)$ & \\
\hline Allele $C$ frequency & 0.163 & 0.151 & \\
\hline \multicolumn{4}{|l|}{ TFPI -33 } \\
\hline$\pi$ & $24(52.2)$ & $89(51.7)$ & $>0.2$ \\
\hline $\mathrm{TC}$ & $21(45.7)$ & $69(40.1)$ & \\
\hline CC & $1(2.2)$ & $14(8.1)$ & \\
\hline Allele C frequency & 0.251 & 0.282 & \\
\hline
\end{tabular}

Calculations are performed with comparison for the heterozygous and homozygous pooled, versus the wild type.

$p$-values refer to differences between diabetes versus non-diabetes.

and arterial thrombosis are multifactorial disorders, including both genetic and environmental factors, we explored further if these genetic variants were linked to gender, T2DM and subtypes of CHD (MI).

\section{Frequencies in the CHD population and controls}

The observed frequencies of the SNPs in the CHD population and healthy controls are mainly in line with other reports [20-26], also investigating CHD in Caucasians. In a Swedish study, in patients with acute coronary syndrome, the TF $5466 \mathrm{~A} / \mathrm{G}$ polymorphism was associated with cardiovascular death, and the CG haplotype, by TF -
$1812 \mathrm{C} / \mathrm{T}$ and TF $5466 \mathrm{~A} / \mathrm{G}$, was associated with a 3-fold increased risk of death [22]. In our study no association between any of the investigated polymorphisms and the presence of stable CHD was observed. It should be noted that the unbalanced number of cases and controls might have influenced the results and the control group was also seven years younger.

We could also not find any association in the subgroup of CHD patients with previous MI. As for the TF-603 A/ $\mathrm{G}$ polymorphism and the association to cardiovascular events, diverging results are reported $[20,21,23]$. No case- 
Table 5: Plasma TF and TFPI levels according to genotypes in the total CHD population

\begin{tabular}{|c|c|c|c|c|}
\hline Genotypes & TF pg/ml* & $\mathbf{p}$ & & \\
\hline \multicolumn{5}{|l|}{ TF -1812} \\
\hline $\mathrm{CC}$ & $150(107,210)$ & & & \\
\hline $\mathrm{CT}$ & $138(96,187)$ & $0.013 t$ & & \\
\hline $\mathrm{TT}$ & $153(109,203)$ & & & \\
\hline \multicolumn{5}{|l|}{ TF -603} \\
\hline AA & $149(107,210)$ & & & \\
\hline AG & $139(97,187)$ & $0.019+$ & & \\
\hline GG & $153(109,203)$ & & & \\
\hline \multicolumn{5}{|l|}{ TF 5466} \\
\hline$A A$ & $143(104,197)$ & & & \\
\hline \multirow[t]{2}{*}{ AG/GG\| } & $154(104,197)$ & $>0.2$ & & \\
\hline & Free TFPI $\mathrm{ng} / \mathrm{ml} \neq$ & & Total TFPI ng/ml‡ & $\mathrm{p}$ \\
\hline \multicolumn{5}{|l|}{ TFPI -399 } \\
\hline $\mathrm{CC}$ & $15.5(4.6)$ & & $68.6(14.1)$ & \\
\hline $\mathrm{CT} / \mathrm{TT} \|$ & $15.1(5.8)$ & $>0.2$ & $64.2(14.9)$ & $<0.001$ § \\
\hline \multicolumn{5}{|l|}{ TFPI -287 } \\
\hline$\pi$ & $15.2(4.9)$ & & $67.2(14.7)$ & \\
\hline $\mathrm{TC} / \mathrm{CC} \|$ & $15.7(4.9)$ & 0.178 & $68.6(13.6)$ & 0.183 \\
\hline \multicolumn{5}{|l|}{ TFPI -33 } \\
\hline $\mathrm{TT}$ & $15.5(5.2)$ & & $63.3(13.3)$ & \\
\hline $\mathrm{TC} / \mathrm{CC} \|$ & $15.3(4.6)$ & $>0.2$ & $72.1(14.1)$ & $<0.001 \S$ \\
\hline $\begin{array}{l}\text { * Values are } r \\
\text { † Kruskall-Wa } \\
\text { ₹ Values are } \\
\text { SIndepender } \\
\| \text { Heterozygo } \\
\text { p-values refe }\end{array}$ & $\begin{array}{l}\text { us are combir } \\
\text { tween genoty }\end{array}$ & 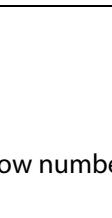 & ozygous. & \\
\hline
\end{tabular}

control differences in frequencies with regard to CHD have been observed for the TFPI polymorphisms [24,25].

\section{Genotypes and phenotypes in the total CHD population}

In our CHD population the heterozygotes for the two linked TF polymorphisms, the TF-1812C/T and the TF$603 \mathrm{~A} / \mathrm{G}$, presented with significantly lower TF plasma levels as compared to the two homozygous genotypes, pointing to a potential protecting role of these polymorphisms. This is somewhat in contrast to the findings from smaller sub-sets in the ECTIM and PATHROS studies [20]. These results were, however, obtained in healthy individuals. We observed no genotype-phenotype association for the TF 5466 SNP, which is in line with the main results from Mälarstig et al. [22]. They could, however, show that the TF mRNA expression was influenced by the SNP. In our study, the TFPI $-399 \mathrm{C} / \mathrm{T}$ and the TFPI -33
$\mathrm{T} / \mathrm{C}$ polymorphisms were associated with lower and higher TFPI total antigen levels, respectively, in line with other reports $[25,26]$. Thus, both protective and harmful role of the single nucleotide polymorphisms might be present. The TFPI $-287 \mathrm{~T} / \mathrm{C}$ did not affect the TFPI plasma levels significantly.

\section{Genotypes and phenotypes as related to gender}

The higher prevalence of the TF 5466A/G polymorphism in women with $\mathrm{CHD}$ has previously not been reported neither the tendency towards a higher prevalence in women for the TFPI $-399 \mathrm{C} / \mathrm{T}$ polymorphism. As the TFPI -399C/T SNP seems to lead to lower levels of TFPI, as shown in our study, and the TF 5466 A/G SNP seems to give higher mRNA levels, shown in another study [22], a possible prothrombotic state with a combined genotype in women with CHD might be suggested. 

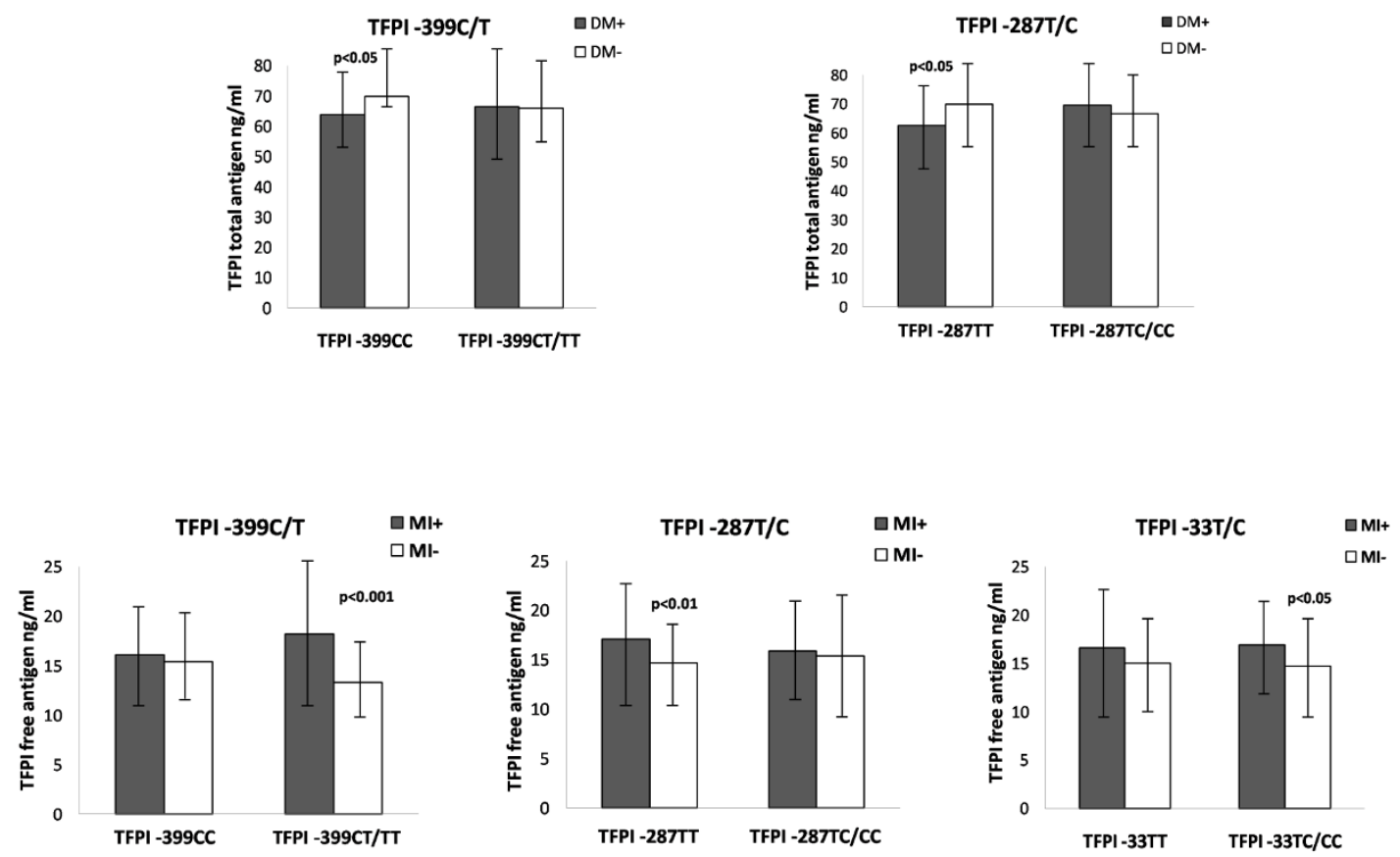

Figure 1

Figure 1 Plasma levels of TFPI in women according to genotypes, T2DM and MI. Levels of TFPI total antigen according to genotypes and T2DM $(n=46)$ in upper panel. Levels of TFPI free antigen according to genotypes and MI $(n=71)$ in lower panel. Values are mean, with error bars representing SD.

\section{Genotypes and phenotypes in women with T2DM}

The $\mathrm{T}$ and $\mathrm{G}$ allele of the TF $-1812 \mathrm{C} / \mathrm{T}$ and the TF -603A/ $\mathrm{G}$ polymorphisms, respectively, were significantly more frequent in women without T2DM as compared to women with diabetes. As the heterozygous state was associated with significantly lower TF levels, women with CHD not presenting with diabetes may be less susceptible to thrombotic events, and a possible causal role of these genetic polymorphisms in the pathogenesis of atherothrombosis in T2DM may be considered. Patients presenting with diabetes have been shown to be more hypercoagulable and prone to acute coronary events, partly through the activation of the TF pathway [28]. As hyperglycemia and hyperinsulinemia is common in patients with T2DM, we propose that the recently shown contribution to the procoagulant state [18], may partly be TF genotype dependent.

The observed lower TFPI total antigen in the present study in women with diabetes was only significant for the TFPI -399 CC and the TFPI -287 TT genotypes, which my indicate that the regulation of TFPI by hyperglycemia to some degree is related to the TFPI genotype. However it should be emphasized that the less frequent genotypes also may play a role.

\section{Genotypes and phenotypes in women with MI}

The frequencies for all SNPs were similar for women with and without previous MI and plasma levels of TF did not differ between the groups. Higher TFPI free antigen levels were observed for this group, especially in individuals bearing the TFPI $-399 \mathrm{CT} / \mathrm{TT}$, the TFPI $-287 \mathrm{TT}$ and the TFPI -33TC/CC genotypes. This association was not observed in men (data not shown). The importance of TFPI in atherothrombotic disease is still controversial. Higher plasma levels of TFPI, which have been reported in CHD patients [9], may reflect a compensatory mechanism due to activation of the TF coagulation pathway, but may also reflect endothelial dysfunction in the atherosclerotic process. The free pool of TFPI includes the fulllength TFPI and generally reflects the changes in endothelial cell-associated TFPI [29], whereas the free form with its strong anticoagulant activity is thought to be important for the function of TFPI in vivo [30]. It may thus be suggested that women are more prone to develop a dysfunctional endothelium. Whether this gender discrepancy in plasma levels of TFPI may be important for the disease progression remains to be elucidated and require further investigation. Notable, as almost all patients were on statin treatment no corrections for cho- 
lesterol, of possible importance for the measurements of TFPI total antigen, have been performed.

\section{Conclusion}

Genetic variations of the TF and TFPI genes seem to be associated with gender in the present population of CHD patients. Women presenting with T2DM showed a different pattern in TF and TFPI genotypes, as compared to women without diabetes, partly related to their respective phenotypes. The phenotype differences observed are minor and within the normal range. However, recent studies have shown that minor increase and decrease in prothrombotic factors and inhibitors, respectively, may induce thrombin generation and subsequent thrombus formation. Thus, a possible enlargement of a TF/TFPI ratio due to genetic variants, may contribute to a hypercoagulable state in CHD, which may be more important for clinical events in women with diabetes. It should, however, be underlined that these results have to be confirmed in studies more specifically designed, due to low number in the different subgroups.

\section{Conflict of interests}

The authors declare that they have no competing interests.

\section{Additional material}

Additional file 1 Plasma TF and TFPI levels according to T2DM (DM), $\mathrm{MI}$ and gender in the total CHD population $(n=1001)$

Additional file 2 Plasma TF and TFPI levels in women according to T2DM (DM) and MI

\section{Authors' contributions}

TBO conducted the study and was responsible for all analysis, drafted and revised the manuscript. Å̊P contributed to the study protocol, acquired data and discussed the manuscript. TW contributed in the interpretation of results and discussed the manuscript. HA contributed to the study protocol, the interpretation of results and discussed the manuscript. IS conducted the study, contributed to the interpretation of results, drafted and revised the manuscript, and gave the final approval of the version to be published. All authors read and approved the final manuscript.

\section{Authors' information \\ TBO: MSc, PhD student \\ AÅP: MD, PhD student \\ TW: MD, PhD student \\ HA: Professor MD PhD \\ IS: Professor PhD}

\section{Acknowledgements}

The authors would like to thank medical laboratory technologists Vibeke Bratseth for blood sample handling in the ASCET-study and Sissel Åkra for excellent technical assistance.

Grants and financial support: This work was supported by the Norwegian Council for Cardiovascular Diseases and Stein Erik Hagen Foundation for Clinical Heart Research.

\section{Author Details}

${ }^{1}$ Center for Clinical Heart Research, Department of Cardiology, Oslo University Hospital Ulleval, Oslo, Norway, ${ }^{2}$ Center for Clinical Research, Oslo University Hospital Ulleval, Oslo, Norway and 3Faculty of Medicine, University of Oslo, Norway

Received: 9 November 2009 Accepted: 5 May 2010

Published: 5 May 2010

\section{References}

1. Giesen PL, Rauch U, Bohrmann B, Kling D, Roque M, Fallon JT, Badimon JJ, Himber J, Riederer MA, Nemerson Y: Blood-borne tissue factor: another view of thrombosis. Proc Natl Acad Sci USA 1999, 96:2311-2315.

2. Girard TJ, Warren LA, Novotny WF, Likert KM, Brown SG, Miletich JP, Broze GJ Jr: Functional significance of the Kunitz-type inhibitory domains of lipoprotein-associated coagulation inhibitor. Nature 1989, 338:518-520.

3. Bajaj MS, Birktoft JJ, Steer SA, Bajaj SP: Structure and biology of tissue factor pathway inhibitor. Thromb Haemost 2001, 86:959-972.

4. Bajaj MS, Kuppuswamy MN, Saito H, Spitzer SG, Bajaj SP: Cultured normal human hepatocytes do not synthesize lipoprotein-associated coagulation inhibitor: evidence that endothelium is the principal site of its synthesis. Proc Natl Acad Sci USA 1990, 87:8869-8873.

5. Broze GJ Jr: Tissue factor pathway inhibitor. Thromb Haemost 1995 74:90-93

6. Lindahl AK, Sandset PM, Abildgaard U: The present status of tissue factor pathway inhibitor. Blood Coagul Fibrinolysis 1992, 3:439-449.

7. Wilcox JN, Smith KM, Schwartz SM, Gordon D: Localization of tissue factor in the normal vessel wall and in the atherosclerotic plaque. Proc Natl Acad Sci USA 1989, 86:2839-2843.

8. Kaikita K, Takeya M, Ogawa H, Suefuji H, Yasue H, Takahashi K: Colocalization of tissue factor and tissue factor pathway inhibitor in coronary atherosclerosis. J Pathol 1999, 188:180-188.

9. Falciani M, Gori AM, Fedi S, Chiarugi L, Simonetti I, Dabizzi RP, Prisco D, Pepe G, Abbate R, Gensini GF, et al:: Elevated tissue factor and tissue factor pathway inhibitor circulating levels in ischaemic heart disease patients. Thromb Haemost 1998, 79:495-499.

10. Freeburn JC, Wallace JM, Strain JJ, Sinnamon DG, Craig BM, Johnson D, Gilmore WS: Monocyte tissue factor-like activity in post myocardial infarction patients. Br J Haematol 1998, 102:605-608.

11. Ott I: Tissue factor in acute coronary syndromes. Semin Vasc Med 2003 , 3:185-192.

12. Morange PE, Blankenberg S, Alessi MC, Bickel C, Rupprecht HJ, Schnabel R, Lubos E, Munzel T, Peetz D, Nicaud V, et al.: Prognostic value of plasma tissue factor and tissue factor pathway inhibitor for cardiovascular death in patients with coronary artery disease: the AtheroGene study. J Thromb Haemost 2007, 5:475-482

13. Seljeflot I, Hurlen M, Hole T, Arnesen H: Soluble tissue factor as predictor of future events in patients with acute myocardial infarction. Thromb Res 2003, 111:369-372.

14. Juutilainen A, Kortelainen S, Lehto S, Ronnemaa T, Pyorala K, Laakso M: Gender difference in the impact of type 2 diabetes on coronary heart disease risk. Diabetes Care 2004, 27:2898-2904.

15. Lundberg V, Stegmayr B, Asplund K, Eliasson M, Huhtasaari F: Diabetes as a risk factor for myocardial infarction: population and gender perspectives. J Intern Med 1997, 241:485-492.

16. Calles-Escandon J, Garcia-Rubi E, Mirza S, Mortensen A: Type 2 diabetes: one disease, multiple cardiovascular risk factors. Coron Artery Dis 1999, 10:23-30.

17. Carr ME: Diabetes mellitus: a hypercoagulable state. J Diabetes Complications 2001, 15:44-54.

18. Boden G, Vaidyula VR, Homko C, Cheung P, Rao AK: Circulating tissue factor procoagulant activity and thrombin generation in patients with type 2 diabetes: effects of insulin and glucose. J Clin Endocrinol Metab 2007, 92:4352-4358

19. Morange PE, Renucci JF, Charles MA, Aillaud MF, Giraud F, Grimaux M, Juhan-Vague I: Plasma levels of free and total TFPI, relationship with cardiovascular risk factors and endothelial cell markers. Thromb Haemost 2001, 85:999-1003. 
20. Arnaud E, Barbalat V, Nicaud V, Cambien F, Evans A, Morrison C, Arveiler D, LuC G, Ruidavets JB, Emmerich J, et al.: Polymorphisms in the $5^{\prime}$ regulatory region of the tissue factor gene and the risk of myocardial infarction and venous thromboembolism: the ECTIM and PATHROS studies. Etude Cas-Temoins de I'Infarctus du Myocarde. Paris Thrombosis case-control Study. Arterioscler Thromb Vasc Biol 2000, 20:892-898.

21. Campo G, Valgimigli M, Ferraresi P, Malagutti P, Baroni M, Arcozzi C, Gemmati D, Percoco G, Parrinello G, Ferrari R, et al: Tissue factor and coagulation factor VII levels during acute myocardial infarction: association with genotype and adverse events. Arterioscler Thromb Vasc Biol 2006, 26:2800-2806.

22. Malarstig A, Tenno T, Johnston N, Lagerqvist B, Axelsson T, Syvanen AC, Wallentin L, Siegbahn A: Genetic variations in the tissue factor gene are associated with clinical outcome in acute coronary syndrome and expression levels in human monocytes. Arterioscler Thromb Vasc Biol 2005, 25:2667-2672.

23. Ott I, Koch W, von Beckerath N, de Waha R, Malawaniec A, Mehilli J, Schomig A, Kastrati A: Tissue factor promotor polymorphism -603 A/G is associated with myocardial infarction. Atherosclerosis 2004, 177:189-191.

24. Moatti D, Seknadji P, Galand C, Poirier O, Fumeron F, Desprez S, Garbarz M, Dhermy D, Arveiler D, Evans A, et al:: Polymorphisms of the tissue factor pathway inhibitor (TFPI) gene in patients with acute coronary syndromes and in healthy subjects: impact of the V264 M substitution on plasma levels of TFPI. Arterioscler Thromb Vasc Biol 1999, 19:862-869.

25. Moatti D, Haidar B, Fumeron F, Gauci L, Boudvillain O, Seknadji P, Olliver V, Aumont MC, de Prost D: A new T-287C polymorphism in the $5^{\prime}$ regulatory region of the tissue factor pathway inhibitor gene. Association study of the T-287C and C-399T polymorphisms with coronary artery disease and plasma TFPI levels. Thromb Haemost 2000, 84:244-249

26. Moatti D, Meirhaeghe A, Ollivier V, Bauters C, Amouyel P, de Prost D: Polymorphisms of the tissue factor pathway inhibitor gene and the risk of restenosis after coronary angioplasty. Blood Coagul Fibrinolysis 2001, 12:317-323

27. Pettersen AA, Seljeflot I, Abdelnoor M, Arnesen $\mathrm{H}$ : Unstable angina, stroke, myocardial infarction and death in aspirin non-responders. A prospective, randomized trial. The ASCET (ASpirin non-responsiveness and Clopidogrel Endpoint Trial) design. Scand Cardiovasc J 2004, 38:353-356.

28. Sambola A, Fuster V, Badimon JJ: [Role of coronary risk factors in blood thrombogenicity and acute coronary syndromes]. Rev Esp Cardiol 2003, 56:1001-1009.

29. Kokawa T, Enjyoji K, Kumeda K, Kamikubo Y, Harada-Shiba M, Koh H, Tsushima M, Yamamoto A, Kato H: Measurement of the free form of TFPI antigen in hyperlipidemia. Relationship between free and endothelial cell-associated forms of TFPI. Arterioscler Thromb Vasc Biol 1996, 16:802-808.

30. Dahm AE, Andersen TO, Rosendaal F, Sandset PM: A novel anticoagulant activity assay of tissue factor pathway inhibitor I (TFPI). J Thromb Haemost 2005, 3:651-658.

doi: 10.1186/1477-9560-8-7

Cite this article as: Opstad et al., Gender differences of polymorphisms in the TF and TFPI genes, as related to phenotypes in patients with coronary heart disease and type-2 diabetes Thrombosis Journal 2010, 8:7

Submit your next manuscript to BioMed Central and take full advantage of:

- Convenient online submission

- Thorough peer review

- No space constraints or color figure charges

- Immediate publication on acceptance

- Inclusion in PubMed, CAS, Scopus and Google Scholar

- Research which is freely available for redistribution

Submit your manuscript at www.biomedcentral.com/submit
C BioMed Central 